\title{
Design of Next Generation Civil and Military Aircraft with Ultra-High Bypass Engine using Composites, Advanced Materials and Technology
}

\author{
B. O. Akinnuli ${ }^{1} \&$ O. J. Oladipo ${ }^{2}$ \\ ${ }^{1}$ Department of Industrial and Production Engineering, The Federal University of Technology, Akure, Nigeria \\ ${ }^{2}$ Department of Mechanical Engineering, The Federal University of Technology, Akure, Nigeria \\ Correspondence: B. O. Akinnuli, Department of Industrial and Production Engineering, The Federal University of \\ Technology, Akure, Nigeria. E-mail: ifembola@yahoo.com
}

Received: November 8, 2018

Accepted: November 20, 2018

Online Published: November 30, 2018

doi:10.5539/mer.v8n2p48

URL: https://doi.org/10.5539/mer.v8n2p48

\begin{abstract}
Indirect combustion noise had not been attracting research in the past, but recent indication seems to prove that it could be a threat in the future if not addressed. Means of reducing this type of noise to a low decibel value was also included. Noise is due to the ingestion of distorted atmospheric turbulence, as the two set of blades rotate in different direction. Open rotor noise is higher since the rotors are fully exposed to oncoming turbulence and lack ducting or a nacelle to attenuate the radiated sound. A thorough review on the technology that can replace conventional turbofan was carried out. It was found that none of this technology can meet up with the ACARE and NASA 2020 vision but left a gap to be filled. Because open rotor is the most proven engine that is able to satisfy this requirements, different methods are adopted and integrated to reduce open rotor noise. Attention was paid to the geometry of the blade, hub and blade length, the vorticity and interaction noise are simulated until an optimized blade was achieved. The integration problem of open rotor was addressed where the engine was located to minimize perceive noise to the payload.
\end{abstract}

Keywords: Aircraft, Composites, Noise, Open rotor, Advanced Technology

\section{Introduction}

Aerospace engineering is an aspect of engineering that deals with the design, maintenance and improvement of aircraft by using knowledge and skills acquired through mathematics, physics, chemistry and natural science. An engineer trained by education and experience can be licensed to practice activities in the aerospace industry; such a professional is regarded as an aerospace engineer.

The major activity in aeronautical profession is aircraft design. Aircraft design requires the integration of experts in disciplines including Aerodynamics, Propulsion, Structures, Flight mechanics, Avionics and Management (Sadraey, 2013). All experts in these fields must have the basic knowledge of engineering design techniques. Aircraft design is an analytical process; it requires creative and innovative mindset. The career goal of any aerospace engineer like other engineers in differ fields is to design aircraft that satisfactorily meets the market demand (Bello, 2018).

Rapid technological advancement has been taken place in the aerospace sector since man first get to space through fixed wing airplane. Today's innovation in aerospace focused on three main areas, these are Environmental impact, Economic efficiency and Improved passenger experience (Special focus, 2018). Environmental impact and economic efficiency are given preference in recent research because of the strict rules and regulations laid down by the regulatory bodies. Such include the Advisory Committee for Aeronautics and Research in Europe (ACARE), the National Aeronautics and Space Administration (NASA), the Intergovernmental Panel on Climate Change (IPCC), Committee on Aviation Environmental Protection (CAEP), Continuous Lower Energy, Emissions and Noise (CLEEN) among others (ACARE, 2003; IPCC, 1999; ICAO, 2007).

A report from the Royal Aeronautical Society summarizes the challenges facing designers of next generation aircraft. "There are challenges facing the next generation aircraft as stricter environmental constraints and increasing pressure to reduce manufacturing and life-cycle costs mean the resulting aircraft will be complex, requiring the use of advanced or novel materials, multi-disciplinary design approaches and solutions operating in a distributed design environment" (RAeS, 2018). These regulations mean that next generation aircraft should be designed to contribute little or no pollution to the environment. This can be achieved using More Electric Engine (MEE), More Electric Aircraft (MEA) or any other aircraft engine that can satisfy these requirements (RAeS, 2018). 
Innovation and improvement in avionics, communication, flight, automation, propulsion and material metallurgy had made it possible to classify both civil and military aircraft into generations (MigFlug, 2018; Mandala, 2007; aerospaceweb, 2018;). The recent improvement is made possible of improved knowledge of composites. Fifth generation commercial aircraft include Boeing 787 and Airbus A380. To be able to enter the next generation, there must be greater improvement in the propulsion system (airliners, 2018).

The requirement for engines that with minimal fuel burn and noise have triggers research and innovation. In the past few years, various concepts have been designed, only few partly satisfy the requirements. Some of these concepts include: the Sugar Volt, MIT N+3, Boeing X48B, AC20.30 model, Northrop Grumman Drake concept, AMELIA, Lockheed Martin box wing airplane, TOSCA, SAI, NASA N+3 CRC among others (RAeS, 2018; AviatonFacts, 2016).

However, Blended Wing Body (BWB) design provides noise shielding; its use is yet to be approved by the certified bodies. This may be partly because it is more difficult to evacuate passengers in emergency and difficulty in control (Roman et al., 2000).

The open rotor engine was introduce by NASA during the oil crisis in the 1970's but was put on hold after the oil price went down (NASA, 1980). Open rotor engine is also known as Unducted fan (UDF), Propfan or Ultra-high bypass engine. It is similar to turbofan engines. One major difference is that it does not have a nacelle to cover the fan (flightglobal, 2018). Open rotor combines the performance of turbofan with the fuel economy of turboprop engine. Contra rotating open rotor (CROP) is the most common type, it has two set of blades that rotate counter clockwise. The aft or rear rotors collect airflow from the front rotor and convert it to thrust. This interaction creates an environment for greater noise to be generated. Open rotor are noisy and this prevents its adoption as jet liner engine (Dale, 2010). The noise problem is a challenge that is yet to be solved. Some of the means of reducing the noise is the focus of this research. This led to the design of a propfan engine with minimum noise emission that decreases fuel burn by having higher propulsive efficiency. The design is integrated to the airframe of an aircraft and simulated to determine the optimum performance of the integrated system.

\section{Methodology}

Different methods (Material optimization, optimized rotor blade, blade clipping, active noise control and MEMs products) were adopted to reduce open rotor noise, by using these accepted method, this research will reduce noise generated from the engine. The two main type of noise in open rotor are the tonal noise and broadband noise. Figure 1 below depicts the various types of noise in an open rotor engine.

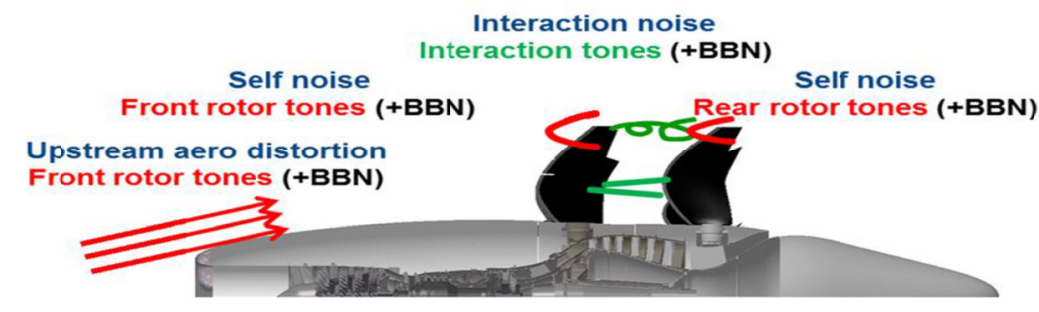

Figure 1. Open Rotor Noise Interaction

Source: Mathieu et al. (2015).

The methods used to achieve the aim and objectives of this research which involves: design analysis of a propfan engine with minimum noise emission, design for a higher propulsive efficiency to decrease fuel burn, integration of the design system into airframe of an aircraft and carry out simulations on the system to evaluate the performance of the designed system is presented here.

\subsection{Design analysis of propfan engine for minimum noise emission}

One of the most acceptable methods is to optimize open rotor blade. An optimal design is capable of addressing open rotor noise. Optimal design involves the use of flow equations such as Euler's equation, Reynolds-average Navier-Stroke Equation (RANS), Biot-Savart's law, Ffowcs-Williams and Hawkings equation (FW-H) and the Kirchhoff equation.

The Euler's equation (Na Gao, 2018) used to predict aerodynamic noise and is given as:

$$
\left[\frac{1}{c_{0}^{2}} \frac{\partial}{\partial t^{2}}-\frac{\partial}{\partial x_{i}^{2}}\right] p^{\prime}(x, t)=\frac{\partial}{\partial t}\left[\rho_{0} v_{n} \delta(f)\right]-\frac{\partial}{\partial x_{i}}\left[P_{i j} n_{j} \delta(f)\right]+\frac{\partial^{2}}{\partial x_{i} \partial x_{j}}\left[T_{i j} H(f)\right]
$$


Where, $\mathrm{C}_{0}$ is the speed of sound, $p^{\prime}$ is the acoustic pressure, $v_{n}$ is the normal component of the surface velocity, $\mathrm{x}$ is the location of the observer, $\mathrm{t}$ is the time, $n_{j}$ is the unit normal vector pointing toward the exterior region, $\delta$ is the shear stress, $T_{i j}$ is the Lighthill stress tensor, $P_{i j}$ is the compressive stress tensor, $\rho_{0}$ is the static density of the fluid without disturbance, $F$ is the Kirchhoff surface and $H(f)$ and $\delta(f)$ are the Heaviside function and Dirac delta function respectively.

An optimal rotor blade involves the computation of the blade parameters to satisfy the required operating conditions and the design of the tip to delay shock and noise interaction. The tip interaction and shock was replaced by pressure changes. The front rotor wake and the vortex interaction with the aft blades are minimized by this method.

Material with high damping capability was used. There are many design considerations in selecting the material for blade design. Such consideration includes stiffness, rigidity, toughness, modulus, strength and damping capability. In this case, damping ability takes dominance over other design requirements. The principle of high damping on free moving particles in small cavities stores vibrating energy for a short time and turns it into thermal energy.

Carbon nanotubes (CNTs) was found to have exceptional properties. Its properties include very high stiffness, low density and high aspect ratio. For these reasons, CNTs was selected as the ideal material for open rotor blade. Its properties was summarized in the Table 1.

Table 1. Mechanical Strength of CNT

\begin{tabular}{llll}
\hline$\sigma_{f}(\mathrm{GPa})$ & $\mathrm{E}(\mathrm{TPa})$ & $\mathrm{F}_{\mathrm{f}}(\mu \mathrm{N})$ & Tube diameter $(\mathrm{nm})$ \\
\hline $150( \pm 45)$ & $0.91( \pm 0.18)$ & 18 & 12.5 \\
\hline
\end{tabular}

Source: Demczyk et al. (2002).

Where $\sigma$ is the shear stress, $\mathrm{E}$ is the Young modulus and $\mathrm{F}$ is the applied force.

CNTs can be produced using methods such as ablation and chemical vapor deposition (CVD). The method used here is the CVD. The matrix to be used is epoxy resin. Several research suggests that the use of epoxy resin as a matrix for CNTs considerably improve its properties. The accepted method for embedding CNTS into the matrix is resin transfer mold (RTM) or resin injection mold (RIM).

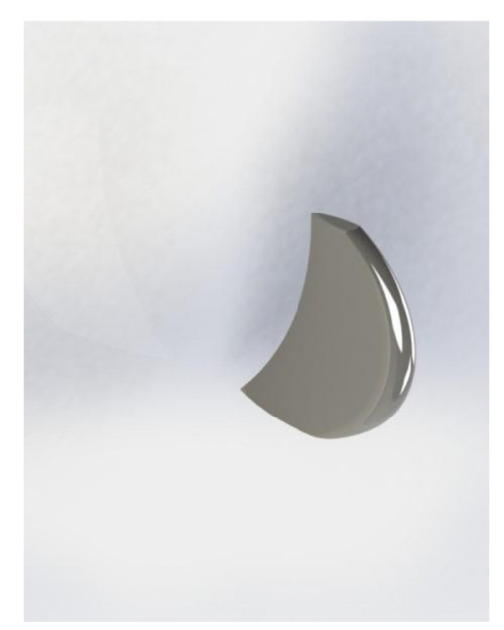

Figure 2a. 3D Optimized Rotor Blade

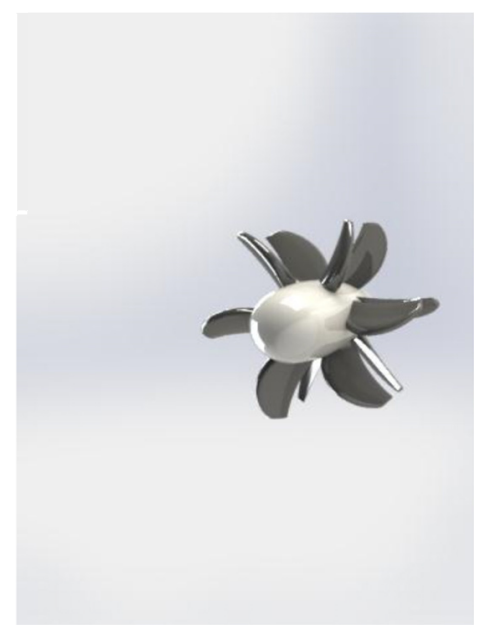

Figure 2b. Optimized blade with Engine nacelle

\subsubsection{Active Noise Control}

Active Noise Suppression system is another means of reducing open rotor noise. The primary principle of active noise control is to sense the noise disturbances in the engine and cancel them before they leave the engine. An actuator inside the stator vanes captures the tones of the fan and sends a $180^{\circ}$ backward to cancel out the noise (AviationFacts.eu, 2016). 


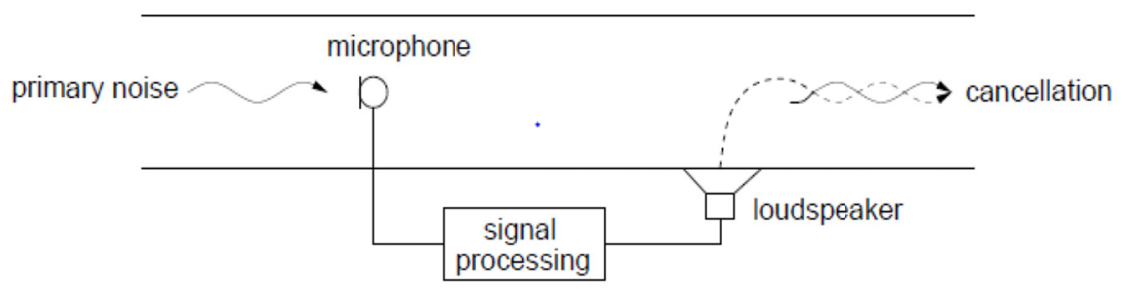

Figure 3. Principle of Active Feed-forward Cancellation of Sound in a Duct

Source: Dieter (2007)

The use of Micro and Nanofabrication (MEMs) product can reduce open rotor noise considerably, this concept is under investigation. MEMs product is used as an accelerometer, for gaming and screen rotation in phones, as microphone to cancel or amplify noise in iPhone and in Electronic Control Unit (ECU) in cars (EPFL, 2018). MEMs product can also be used with composites to trigger device such as airbag to detect crack.

\subsubsection{Acoustic Treatment}

Acoustic treatment has limited use in open rotor because of the absence of nacelle but liners made of honeycomb can be used inside the duct to lower combustion noise. In the nearest future, acoustic liner may be of greater use to reduce combustion noise. Combustion noise is often neglected but it is becoming a major source of noise, MEMs products and piezoelectric materials will be widely used in design. Piezoelectric materials generate electricity when subjected to mechanical stress. The blades can also be treated with liners.

\subsubsection{Blade Clipping}

Blade clipping will be an option if all acceptable method does not lower the noise to an acceptable level. The aft blades are clipped to reduce wake and vortex interaction. The only disadvantage is that thrust will be reduced. It is advisable not to clip more than $25 \%$.

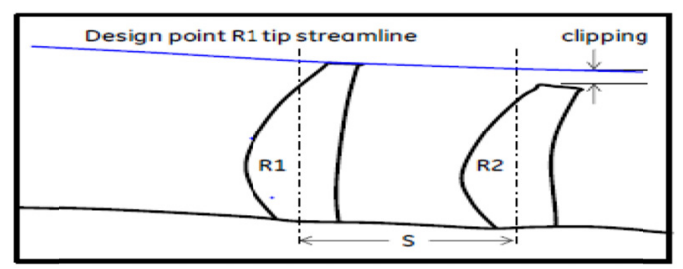

Figure 4. Clipping of an Open Rotor, (NASA, 2010)

In summary, the technologies that can be used to reduce open rotor noise will strongly depend on the design changes that can be made, the disk loading, production method and blade clipping. All these methods must reduce open rotor noise by $35 \mathrm{~dB}$; failure to reduce the noise level by up to $30 \mathrm{~dB}$ will require a redesign.

\subsection{Design for Higher Propulsive Efficiency to Decrease Fuel Burn}

Open rotor engine or propfan reduces fuel burn thereby reducing emission (Torenbeek, 2013). It can reduce fuel burn by twenty-five to thirty per cent $(25-30 \%)$, for this reason open rotor was considered as the type of aircraft engine that can meet NASA and ACARE goal.

Open rotor is very efficient when the speed is not more than Mach 0.8. It was observed that the diameter of the blades has influence on the Mach number, therefore rotor blades of higher diameter was used to increase the tip speed and Mach number. This was complimented by integrating the engine away from under the wing.

\subsection{Integration of the System into Airframe of an Aircraft}

It is required that the engine should not be under the wing to increase the blade diameter, improve passenger comfort by reducing perceived noise and minimize risk if engine burst takes place. The best configuration is as shown below. 


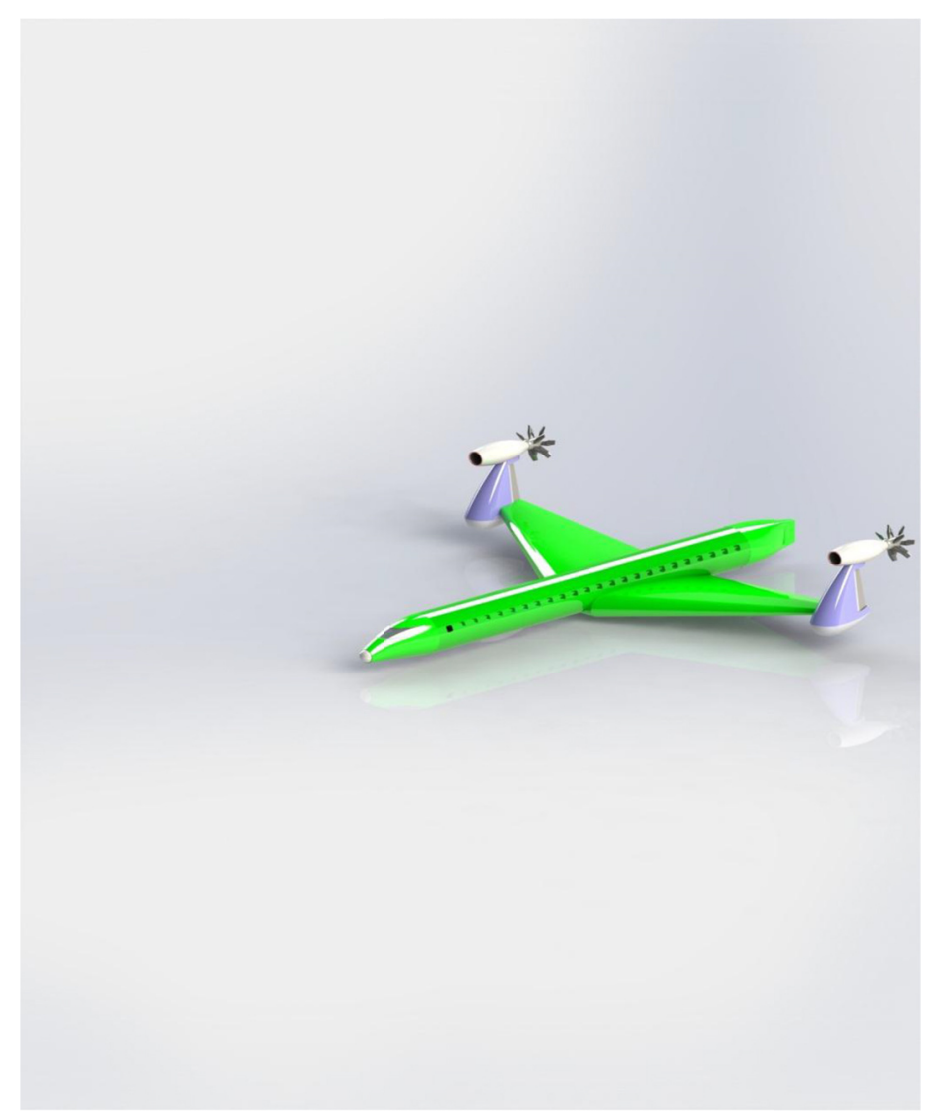

Figure 5. Next Generation Airplane Concept

\subsection{Design System Simulation for Its Performance Evaluation}

Numerical analysis using Hanson's near-field frequency shows that the frequency is been transmitted from the tip of the wing to the wing root. The result shows that using shorter wingspan may lead to undesirable bending and flutter. The system was redesigned and the best compromise was arrived (Figure 2) by using a wingspan between 69.8-79.8m.

\subsubsection{Simulation Flow Chart}

The simulation flow chart used was extracted and modified from the Hanson's flowchart prediction process (Anupam S and Hsuan-nien C). It is shown below.

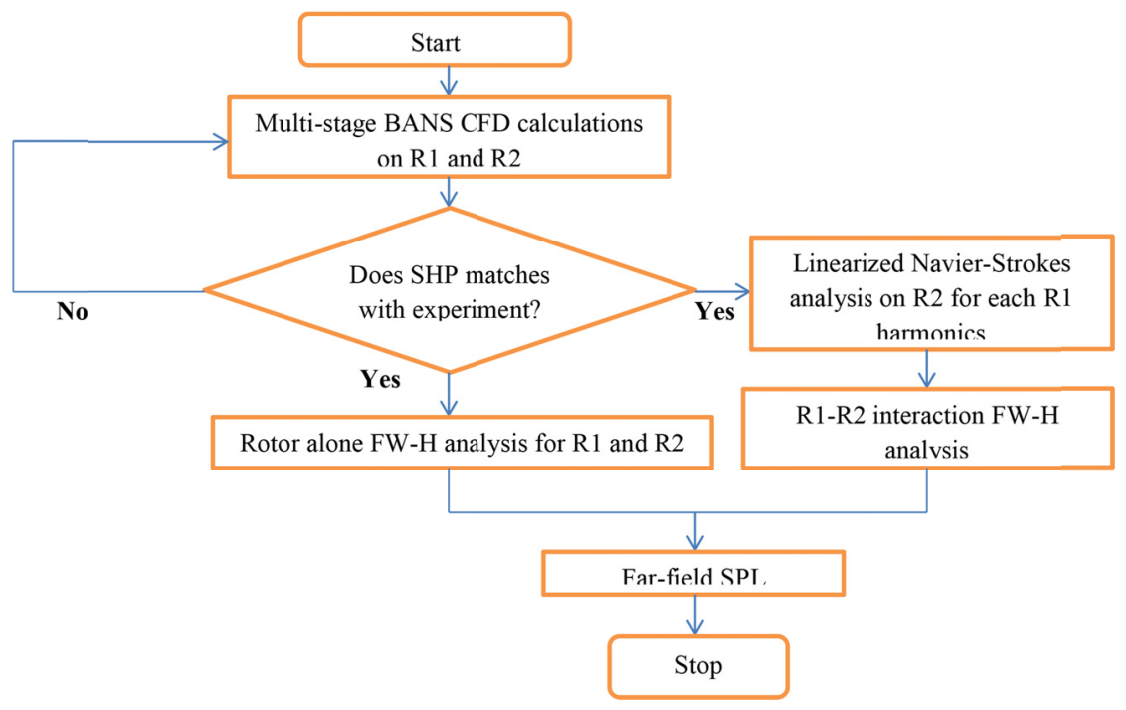




\subsection{Design Diagram of the System}

The components designed include an optimized rotor blade, optimized blade with the engine nacelle and an aircraft integrated with open rotor engine. These are shown in Figure 2a, $2 \mathrm{~b}$ and 4 respectively.

\section{Result and Discussion}

Numerical Computation of Open Rotor Noise is carried out and the results is as shown in Figure 6a and $6 \mathrm{~b}$ respectively. Some assumptions that are made include the following:

$$
\mathrm{M}=0.85, \quad \gamma=1.4, \propto=30^{\circ}, \mathrm{M}_{\infty}=10 \text {, The wing is also assumed to have uniform pressure. }
$$

Where $\mathrm{M}$ is the Mach number, $\gamma$ is the compressibility ratio, $\propto$ is the angle of attack and $\mathrm{M}_{\infty}$ is the Mach number at infinity.

The surface pressure coefficient is given as:

$$
C_{p}=\left(P_{b}-P_{\infty}\right) / 0.5 \rho_{\infty} U_{\infty}^{2}
$$

Where $C_{P}$ is the coefficient of pressure, $\mathrm{P}$ is the general field point, the subscripts $\mathrm{b}$ and $\infty$ stands for domain of propagation and infinity respectively, $\rho_{\infty}$ is the fluid density and $U_{\infty}$ is the freestream velocity.

To be able to determine the far-field acoustic, boundary element method must be used. It is governed by the equation

$$
C(P) p(P)=\int_{s}\left(\frac{\partial G(Q, P)}{\partial n} p(Q)-G(Q, P) \frac{\partial p(Q)}{\partial n}\right) d S(Q)
$$

Where $\mathrm{Q}$ is the source point, $\mathrm{G}$ is the Green's function, $\mathrm{n}$ is the normal unit at $\mathrm{Q}$ and other parameters are the same as that of equation 3.1

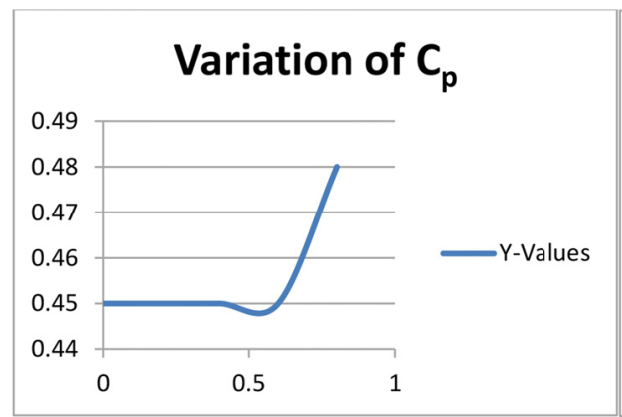

Figure 6a. Variation of $\mathrm{Cp}$ with $\propto$

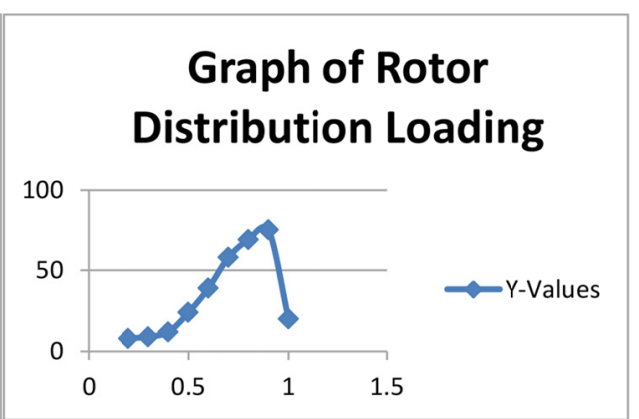

Figure 6b Rotor Distribution Loading

The acoustic pressure equation used was

$$
\frac{\partial G(Q, P)}{\partial n}=-\frac{e^{-i k r}}{4 \pi r}\left(\mathrm{ikr}+\frac{1}{r}\right) \cos \beta
$$

Where $\beta$ is the angle between $n$ and $r$. ikr are nodes on acoustics surrounding and other parameters remains constant.

The result shows that the frequency of the open rotor increases slightly from the tip of the wing to the root, therefore the root have to be reinforced more at the root to enable the engine operate effectively at Mach 0.8 and above.

From Figure 6b, it can be shown that the blade distribution loading increases at takeoff condition but decreases after reaching its peak. This implies that the geometry and parameters of the rotor blade has a great influence on the Sound Pressure Level (SPL). Thus, the use of an optimized blade is validated and the predictions validated.

\section{Conclusion}

In conclusion, by using advanced technologies and composites, the next generation aircraft has been designed, it shows greater improvement as compared to the recent generation, noise emission has been reduced using different methods (reference to section 2.0).

The objectives of the research were validated as the optimized rotor blades shows greater reduction in noise, this is evaluated to be $18 \mathrm{~dB}$, while clipping of aft blades by $25 \%$ reduces the noise by $7 \mathrm{~dB}$, active noise control presents a 
gap that requires further research this is to reduce combustion noise but it does appear that this method could reduce noise by more than $5 \mathrm{~dB}$.

The use of open rotor engine can also be extended to military aircraft but in cases where hypersonic speed is required, successful flight will rely on yet to be proven scramjet engine. Advanced technologies nonetheless will help to alleviate most of the problems associated with scramjet engine. The only solution to the challenges facing the aerospace industry is to use advanced technologies.

\section{References}

Advisory Council for Aeronautics Research in Europe. (2007). Retrieved from www.acare4europe.org

Aerospaceweb. (2018). Aircraft History. Retrieved from www.aerospaceweb.org.

Airliners. (2018). Airliner Generations. Retrieved from www.airliners.net

Anderson, J. D. (2001). Fundamentals of Aerodynamics (3rd Ed.). New York: McGraw-Hill.

Baumeister, K. J., (1982). Evaluation of Optimized Multi-sectioned Acoustic Liners. AIAA Journal, WA, 1185-1192

Bayers, D. C. (1984). The NASA Electric Propulsion (pp. 24-29). Ohio.

Bello, E. I. (2018). Aircraft Design Lecture Series. Federal University of Technology, Akure, Nigeria.

Bousquet, J. M. (1986). Theoretical and Experimental Analysis of High Speed Propeller Aerodynamics. Proceedings of 22nd AIAA/ASME/SAE/ASEE, Alabama.

Brouwer, H. (2016). The Scattering of Open Rotor Tones by a Cylindrical Fuselage and Its Boundary Layer. 2nd AIAA/CEAS Aeroacoustics Conference.

Carbon for Electronics. (2018). Retrieved from www.cnanotech.com

Chen, C. S., Velkoff, H. R., \& Tung, C. (1987). Free-wake Analysis of a Rotor in Hover. Proceedings of 19th AIAA Fluid Dynamics and Lasers Conference, Honolulu, Hawaii.

Ci, L., \& Bai, J. (2006). The Reinforcement Role of Carbon Nanotubes in Epoxy Composites with Different Stiffness.

Dale, V. Z. (2010). Open Rotor Technology.

Demczyk, B. G., Wang, Y. M., Cumings, J., Hetman, M., Han, W., Zettl, A., \& Ritchie, R. O. (2002). Direct mechanical measurement of the tensile strength and elastic modulus of multiwalled carbon nanotubes. Materials Science and Engineering: A, 334(1-2), 173-178.

Dieter, G. (2007). Active Control of Sound and Vibration, University of Gottingen, Germany. Ecole Polytechnique Federale De Lausanne (EPFL, 2018). Micro and Nanofabrication. Online Course module, Lausanne, France.

Flightglobal. (2018). Open Rotor: how does it work?. Retrieved from www.flightglobal.com

Gruber, M., Lonfils, T., Dumont, C., Vion, L., Dubois, A., \& Mc Williams, T. D. (2015, June). On the fast prediction of open rotor tonal interaction noise. In ASME Turbo Expo 2015: Turbine Technical Conference and Exposition (pp. V02BT41A006-V02BT41A006). American Society of Mechanical Engineers.

Intergovernmental Panel on Climate Change. (1999). Aviation and the Global Atmosphere, Summary for Policymakers. Geneva.

International Civil Aviation Organization. (2007). Air Transport Bureau (ATB): Environmental (ENV) Unit, Aircraft Noise. Retrieved from www.icao.int

Mandala. (2007). Airliner Generations. Retrieved from www.airliners.net

MigFlug. (2018). Fighter Jet Generations - Military Aviation History. Retrieved from www.migflug.com

Mohammadreza, A., Naghmeh, J. \& Fathollah, O. (2014). Using Acoustic Liner for Fan Noise Reduction in Modern Turbofan Engines. International Journal of Aeronautical \& Space Sci. , 15(1), 97-101.

Na Gao. (2018). Numerical Prediction of the Aerodynamic Noise From the Ducted Tail Rotor.

National Aeronautics and Space Administration. (1980). Dryden Flight Research Center, Ohio. Open Rotor Engine. Retrieved from www.dfrc.nasa.gov

National Aeronautics and Space Administration. (2010). NASA Open Rotor Noise Research. Dryden Flight Centre, Ohio. 
Ngoc Anh Vu, J. W. (2011). Aerodynamic design optimization of helicopter rotor blades including airfoil shape for hover performance. Chinese Journal of Aeronautics, 4-5.

Pachauri, R. K., \& Jallow, B. (2007). Intergovernmental Panel on Climate Change. Retrieved from www.ipcc.ch

Pierluigi, D. V., Daniele, M., Fabrizio, N., \& Agostino, D. (2018). Numerical Analysis of Propeller Effects on Wing Aerodynamic: Tip Mounted and Distributed Propulsion.

Progress towards Open Rotor Propulsion Technology. (2012). Retrieved from www.aerosociety.com

Properties of Carbon Nanotubes. (2018). Retrieved from www.understandingnano.com

Rich, W. (2010). Integrated Solutions for Fuel, Noise, and Emission Reduction. NASA Ames Research Centre.

Roman, D., Allen, J., \& Liebeck, R. (2000). Aerodynamic Design Challenges of the Blended-Wing Body Subsonic Transport. 18th Applied Aerodynamic Conference, Denver, CO, USA.

Sadraey, M. H. (2013). AIRCRAFT DESIGN USA.

Sawdy D. T, Beckemeyer, R. J., \& Petterson, J. D. (1976). Analytical and Experimental Studies of an Optimum Segmented Acoustic Liners for Flow Ducts (pp. 3-7). San Francisco, CA.

Sell, J. (1996). Cascade Testing to Assess the Effectiveness of Mass Addition/Removal Wake Management of Rotor-Stator Interaction Noise. Ph.D. Thesis, MA, USA.

Sharma, A., \& Hsuan-nien, C. (2016). Prediction of Tonal Aerodynamic Noise from Open Rotors. General Electric Global Research Center, One Research Circle, Niskayuna, NY. Retrieved from www.AviationFacts.eu

Special Focus. (2018). Aerospace and Aeronautics. Retrieved from www.eu-japan.eu

SUGAR Volt. (2018). Boeing Hybrid Electric Aircraft. Retrieved from www.youtube.com/watch?v=oz3tzG9RxK

Takahashi, M. D. (1990). A Flight Dynamic Helicopter Mathematical Model with a Single Flap-Lag Torsion Main Rotor (pp. 5-8). Washington DC.

Torenbeek, E. (2013). ADVANCED AIRCRAFT DESIGN. Netherland.

Viba, J., Beresnevich, V., Noskovs, S., \& Irbe, M. (2016). Investigations of Rotating Blade for Energy, Extraction from Fluid Flow (pp. 312-315). Kaunas, Lithuania.

Viba, J., Eiduks, M., \& Irbe, M. (2015). Double Pendulum Vibration Motion in Fluid Flow. International Conference "Engineering for Development" (pp. 434-439). Jelgava, Latvia.

What Commercial Aircraft Will Look Like in 2030. (2018). Retrieved from www.iflscience.com

Wilke, M. I. (n.d.). Passive Blade Optimization and Evaluation in Off-Design Condition. Germany.

William, R. W. (2011). Airfoil Aeroacoustics: LES and Aeroacoustic Analogy Prediction. Stanford University.

World Health Organization. (2011). Burden of Disease from Environmental Noise.

Zhao Ke, G. Z. (2015). Aerodynamic optimization of rotor airfoil based on multi-layer hierarchical constraint method. Chinese Journal of Aeronautics, 1545-1546.

\section{Copyrights}

Copyright for this article is retained by the author(s), with first publication rights granted to the journal.

This is an open-access article distributed under the terms and conditions of the Creative Commons Attribution license (http://creativecommons.org/licenses/by/4.0/). 